\title{
Optimization of the Activated Carbon Preparation from Avocado Seeds, using the Response Surface Methodology
}

\author{
TAGNE TIEGAM RUFIS FREGUE ${ }^{1}$, IOANA IONEL ${ }^{2 *}$, ANAGHO SOLOMON GABCHE ${ }^{1,3}$, ALIN-CRISTIAN MIH AIUTI ${ }^{2 *}$ \\ ${ }^{1}$ Research Unit of Noxious Chemistry and Environmental Engineering, Department of Chemistry, Faculty of Science, University \\ of Dschang, P.O.Box 67, Dschang, Cameroon \\ 2Politehnica University of Timisoara, Faculty of Mechanical Engineering, 1 M. Viteazu Blvd., 300222, Timisoara, Romania, \\ ${ }^{3}$ Department of Chemistry, Faculty of Science, the University of Bamenda, P.O.Box 39, Bambili, Cameroon,
}

\begin{abstract}
Avocado seeds based activated carbon was prepared using chemical activation method which consisted of potassium hydroxide treatment. The main factors influencing the preparation of activated carbons at the calcination temperature, the concentration of the activating agent and the duration of calcination were investigated. One used as a mathematical model the response surface methodology to correlate the response. The significant factors identified by the analysis of variance (ANOVA) through the t-test, the Pareto diagram and the diagrams of surfaces. The optimum avocado seeds based activated carbon was obtained by using calcination temperature of $450^{\circ} \mathrm{C}$, concentration of activating agent of $0.3 \mathrm{~mol} / \mathrm{L}$ and time of calcination of $3.0 \mathrm{~h}$, which resulted to an avocado seed based activated carbon iodine number remove of $1142.1 \mathrm{mg} / \mathrm{g}$ and yield of $75.09 \%$, by mass. The best activated carbon obtained under the previous conditions and the raw biomass was characterized by Fourier transform infrared and Scanning Electronic Microscope.
\end{abstract}

Keywords: activated carbon, avocado seeds, central composite design, optimization

In recent years, solid waste management ranked equal to water and air pollution as the most intricate environmental turmoil in Cameroon. With circulareconomy legislation being introduced in Cameroon, desired direction of solid waste management was oriented towards waste minimization, resource and materials reuse. All strategies adopted were aimed to decrease quantity of solid wastes needing disposal and create available products. Cameroon as one of the largest agricultural country, its vast agricultural wastes were produced annually. However, these wastes were underutilized and often burned in open field, thus causing heavily environmental pollution. The recovery of waste is of particular interest to the extent that it allows the disposal of waste by obtaining quality products economically[1]. Accordingly, the use of agricultural wastes for fabrication of value-added materials seems very attractive and promising from environmentally and economically viable view.

Activated carbon (AC), as a well-knownmultiporousmaterial, was widely used in various fields, such as separation and concentration of useful or harmful components from mixed liquids or gases, and catalyst support [2-7]. However, the manufacture remove costs of commercial $A C$ are in fact rather high $[8,9]$. As such, it is urgent to produce $\mathrm{AC}$ from cheaper, renewable and readily available materials. Recently, some agricultural wastes, such as rambutan peel [2], oil palm fibber [3], bamboo waste [4], cotton stalks [5], mango-steen peel [10] and artichoke leaves [11] were commonly used to prepare AC.

In the literature, physical activation and chemical activation are the two methods used to produce activated carbons [ 6,12 , and 13]. Based on previous works on these methods of preparation, chemical activation has been chosen as the method to prepare activated carbon in this work. Its advantages are simplicity, shorter production time, lower activation temperature, good development of the porous structure and higher yield [14-15].In the chemical activation process, both carbonization and activation stepsprecedesimultaneously bycarrying out thermal decomposition of the raw material impregnated with anappropriatechemical activatingagent, such as phosphoric acid in an inert atmosphere $[17,18]$. These impregnating materials are used as dehydrating agents and oxidants that influence pyrolytic decomposition and inhibit the formation of tar, thus enhancing the yield of activated carbon $[15,19]$. The quality ofactivated carbon obtained depends mainlyon the precursor-material used and the preparation conditions $[20,21]$.

To investigate the effect of some factors on the production of activated carbons, a number of the factors are kept fixed at a certain level, while varying one other so as to determine the best condition for this parameter. Thedisadvantage of this method is that,there is a lack of research on the interactive effects of these factors studied, and that, there is a large number of experiments required, which consequently requires more time $[22,23]$. The evaluation of the interactions between these factors is essential in determining the characteristics oftheprepared activated carbons.

The response surface methodologymade it possible to study several factors simultaneously (temperature of pyrolysis, concentration of activating agent and the duration of the stay in the furnace) intervening in the preparation of the activated carbon by chemical process of activation. The aim of the study is of double interest. First of all, it is a question of optimizing the factors influencing the method of preparation of the activated carbon by chemical activation with the Potassium hydroxide. In the second place, to develop the local biomasses by using them like precursors of the activated carbon, considering the annual production of co-products agricultural like the lawyer cores, remove cocoapods and the peanut shell in the under-area Central Africa is about thousands of tonnes. 


\section{Experimental part}

\section{Preparation of activated carbon}

The avocado seeds were used as raw materials to produce activated carbons by chemical activation with Potassium Hydroxide follow ed by carbonization. The seeds were obtained from the local Menoua Subdivision, in the West Region, in Cameroon. Raw materials were initially washed twice with pure water to remove dust and subsequently dried at $105^{\circ} \mathrm{Cfor} 24 \mathrm{~h}$ to remove moisture content. Then, dried raw material was ground and sieved to size of $1-2 \mathrm{~mm}$. Afterwards, $10 \mathrm{~g}$ sieved particles was selected to mix with Potassium Hydroxide pellets with one impregnation ratio (IR) 1:10 and (50ml) deionised water was added to dissolve all Potassium Hydroxide pellets with different concentrations.

The IR was estimated from equation 1 :

$$
I R=\frac{\text { mass of } \mathrm{KOH}}{\text { mass of raw material }}
$$

The mixture was left overnight at room temperature and then dried at $110^{\circ} \mathrm{C}$ for $24 \mathrm{~h}$. The dried material was set on a ceramic boat which was then inserted in a stainless tube and pyrolysis in furnace and heating rate of $5^{\circ} \mathrm{Cmin}$ "1. Temperatures and times were based on design of RSM (Response Surface Methodology) shown in tablel. After pyrolysis, furnace was cooled to room temperature. Afterwards, obtained samples were washed with $1 \mathrm{~mol} / \mathrm{L}$ $\mathrm{HCl}$, and then with distilled water to make effluent $\mathrm{pH}$ close to 7 . Then, $A C$ samples were dried at $120^{\circ} \mathrm{C}$ for $24 \mathrm{~h}$, sieved and stored in plastic containers for measurement.

\section{Experimental part}

The preparation of activated carbon was optimized using response surface methodology. A central composite design methodology was employed to describe and optimize this preparation process. Three independent variables were used in this study: the temperature, concentration and time of calcination. There are several types of use plans for optimizing a response surface such as: central Composite design, Three-Level Factorial design, Box-Behnken design and Draper-Lin design. In this work, the authors' choice was focused on the central Composite design of making benefits (The ease of using experimental data, the simultaneous variation between several input factors, possibility of determining the regression coefficient for a second-order equation and the interpolation of the response from the factors)[24]. Applying this method, 17 complex experiments were performed, with two repetitions.

$X_{1}, X_{2}$ and $X_{3}$ represent the quantitative factors that influence carbon preparation. The ranges of three factors to evaluate were: $450 \leq X_{1} 600^{\circ} \mathrm{C} ; 0.3 \leq X_{2} 0.6 \mathrm{~mol} / \mathrm{L}$; and $1 \leq X 3$ h. Response $Y$ values were yield $\left(Y_{1}^{2} \%\right)$ and iodine number $(Y, m g / g)$ of $A C$. In the optimization process based on the response surface methodology, obtaining model equations for an input factor response is an important step [24]. The iodine number and yield $(\mathbf{Y})$ responses are analysed, and one used a developed, model which correlates the response to the three variables, using a polynomial equation given by formula 2 [24]:

$$
\begin{aligned}
& \mathbf{Y}=I+a X_{1}+b X_{2}+c X_{3}+d X_{1}^{2}+e X_{1} X_{2}+ \\
& f X_{1} X_{3}+g X_{2}^{2}+h X_{2} X_{3}+i X_{3}^{2}+\varepsilon
\end{aligned}
$$

where:

$Y$ is the measured response,

l-a constant,

$a, b$ and $c$ - linear coefficients,

$d, g$ and $i$ - quadratic coefficient,

$e, f$ and $h$ - less interaction coefficient,
$X_{1}, X_{2^{\prime}}, X_{3^{\prime}}, X_{1}^{2}, X_{1} X_{2}, X_{1} X_{3^{\prime}}, X_{2}^{2}, X_{2} X_{3^{\prime}}, X_{3}^{2}$-the coded values of the activated carbons preparation variables.

$\varepsilon$ - the error.

The experimental data were analysed using a statistical software design expert named StatgraphicPlus 5, for regression analysis to fit the equations developed and also to evaluate the statistical significance of the equations obtained.

\section{Validation of the model}

It is important to validate the empirical model obtained and to do that. The exactitude of the model has to be proven by comparing the responses of the experimental values obtained with the values obtained during manipulation with those obtained from the mathematical model, the t-test, and the values of the probability $p$. All make it possible to determine the significant degree of each coefficient. If the value of the t-test is large and the value of $p$ low, then the coefficient is more significant [25]. In addition to that, the coefficient of determination $\mathrm{R}^{2}$ was evaluated and for an $R^{2}$ value greater than 0.75 , one considered the model accepted. Foran easy calculation, input factors are usually coded with -1 , representing the smallest value, 0 being the centre of the domain and 1 being the largest input value [25].

Table 1

CODED AND ACTUAL LEVEL FOR INDEPENDENT FACTORS USED IN THE EXPERIMENTAL DESIGN

\begin{tabular}{|c|c|c|c|}
\hline \multirow{2}{*}{ Parameters } & \multicolumn{3}{|c|}{ Coded Level } \\
\cline { 2 - 4 } & -1 & 0 & +1 \\
\cline { 2 - 4 } & \multicolumn{3}{|c|}{ Actual Level } \\
\hline Temperature $\mathrm{X}_{1}\left({ }^{\circ} \mathrm{C}\right)$ & 450.0 & 525.0 & 600.0 \\
\hline Concentration $\mathrm{X}_{2}(\mathrm{~mol} / \mathrm{L})$ & 0.3 & 0.45 & 0.6 \\
\hline Time $\mathrm{X}_{3}(\mathrm{~h})$ & 1.0 & 2.0 & 3.0 \\
\hline
\end{tabular}

Measurement of iodine number and yield of activated carbon

The determination of yield in this work allows us to estimate the amounts of activated carbon that can be obtained from an initial amount of dry bio-mass. The activated carbon yield $Y_{1}$ was calculated using the formula 3 [28]:

$$
\text { Efficiency (\%) }=\frac{\text { (initial mass }- \text { final mass })}{\text { initial mass }} \times 100 \text { (3) }
$$

The characterization of the activated carbon by the iodine number gives an idea of its micro porosity. The experiment consists in putting the activated carbon in contact with a solution of known concentration of iodine [13]. The activated carbon thanks to its pores fixes the molecules of the $I_{2}$ (di-iodine) during this contact. To determine this iodine number, oneput in a $100 \mathrm{~mL}$ Erlenmeyer flask, weighed using a precision balance, 0.1 $\mathrm{g}$ of activated carbon. One added $30 \mathrm{~mL}$ of a $0.02 \mathrm{~N}$ (normal) diode solution. According to the standards established by the American Society for Testing and Materials (ASTM) [14], the mixture was stirred for $3 \mathrm{~h}$ and filtered with Whatman $\mathrm{N}^{\circ} 1$ filter paper. Afterwards, $10 \mathrm{~mL}$ of the filtrate was titrated with $0.005 \mathrm{~N}$ sodium thiosulfate solution. [14]

The iodine number $Q$ is obtained from the relation 4

$$
\mathrm{Q}=\frac{\left(c_{0}-c_{t}\right)}{M} \mathrm{~V}
$$

where:

$M(\mathrm{~g})$ is the mass of the activated carbon,

$V(\mathrm{~mL})$ - the volume of the sodium thio-sulphate solution at the equivalence point,

$C_{o}$ - the initial concentration, 
$C_{f}$-the equilibrium concentration.

\section{Results and discussions}

The main constituents of biomass

The purpose of this analysis was to determine the content of the main constituents of biomass. One used different method.

\section{$X$-ray fluorescence}

$X$-ray fluorescence spectrometers allow to present trace elements present in biomass. Table 2 gives the expressed composition in $\mathrm{mg} / \mathrm{kg}$ dry matter.

\begin{tabular}{|c|c|}
\hline Element & $\begin{array}{c}\text { Avocado seeds(mg/kg, } \\
\text { dry matter) }\end{array}$ \\
\hline Zirconium, $\mathrm{Zr}$ & 7081 \\
\hline Lead, $\mathrm{Pb}$ & 1396 \\
\hline Zinc, $\mathrm{Zn}$ & 2470 \\
\hline Copper, $\mathrm{Cu}$ & 92 \\
\hline Iron, $\mathrm{Fe}$ & 763 \\
COMPOSITION IN \\
Table 2 \\
\hline Manganese, $\mathrm{Mn}$ & - \\
\hline Calcium, $\mathrm{Ca}$ & - \\
\hline Potassium, $\mathrm{K}$ & $32.3 \cdot 10^{3}$ \\
\hline Chromium, $\mathrm{Cr}$ & - \\
\hline
\end{tabular}

Table 3 gives the main components of avocado seed, obtained according to standard protocols [26].

Table 3

THE MAIN COMPONENTS OF THE BIOMASS (AVOCADO SEED)

\begin{tabular}{|c|c|}
\hline Parameters & $\begin{array}{c}\text { Content (\%bymass, } \\
\text { dry matter) }\end{array}$ \\
\hline Total solid & 84.28 \\
\hline Volatile solid & 63.22 \\
\hline Total moisture & 15.48 \\
\hline
\end{tabular}

Optimization of activation temperature, time and concentration of agent activating by response surface methodology (RSM)

Statistical experimental design is an efficient way to improve experimental works, has been widely used in chemistry, food and environmental engineering [13-12].
Among these design methods, RSM is considered as a powerful technique for testing multiple process variables and identifying interactions between these variables, and a combination of factors generating an optimal response can be identified by this technique[13]. Besides the quality of the raw materials, external parameters of activation temperature, calcination time and concentration play key roles in AC preparation, accordingly, to determine optimal preparation conditions. RSM experiment was applied and yield $\left(Y_{1}\right)$ and iodine number $\left(Y_{2}\right)$ were analysed as response values. Each factor has three levels and corresponding 17 experiments were designed. Each experiment was carried out in duplicate and repeated twice and the average of experimental results was used.

Optimization of iodine number and yield of avocado seed

Table 4 shows the complete design matrices together with both the response values obtained from the experimental work. The predicted values of responses were obtained fromquadratic model fitting techniques using the software design expert.

The negative difference shows that the experimental value is lower than the realone.

The direct observation of the results allows affirming that the yields vary ( 55.12 and $77.72 \%$ by mass and 342.63 $\mathrm{mg} / \mathrm{g}$ and $1203.01 \mathrm{mg} / \mathrm{g}$ ) for the iodine number. The highest values of the yields are obtained when the temperature $\left(450^{\circ} \mathrm{C}\right)$ and the carbonization time $(1 \mathrm{~h})$ are low, while the best yields are obtained when the temperature $\left(525^{\circ} \mathrm{C}\right)$ and the calcination time ( $3 \mathrm{~h}$ ) are high. This variation can be explained by the fact that an increase in temperature facilitates the breaking of the bonds of the biomass thus facilitating the release of the volatile matter and consequently causes a gradual decrease in the mass of the compound.

For the iodine number, the best values are temperature $\left(450^{\circ} \mathrm{C}\right)$, concentration of the activating $(0.6 \mathrm{~mol} / \mathrm{L})$ and the duration of calcination ( $3 \mathrm{~h}$ ), while low values are obtained at temperature $\left(525^{\circ} \mathrm{C}\right)$, concentration $(0.4 \mathrm{~mol} / \mathrm{L})$ and duration/time (3h). Indeed, one can say that the decrease of the temperature with the increase of the concentration of the activating causes an opening and a widening of the pores and consequently an increase of the adsorption of the molecules of iodine.

\begin{tabular}{|c|c|c|c|c|c|c|c|c|c|}
\hline Run & \multicolumn{3}{|c|}{ Factors } & \multicolumn{3}{c|}{$Y_{1}(\%)$} & \multicolumn{3}{c|}{ Y $_{2}(\mathrm{mg} / \mathrm{g})$} \\
\hline No & $\begin{array}{c}\mathrm{X} 1 \\
\left({ }^{\circ} \mathrm{C}\right)\end{array}$ & $\begin{array}{c}\mathrm{X} 2 \\
(\mathrm{~mol} / \mathrm{L})\end{array}$ & $\mathrm{X} 3(\mathrm{~h})$ & $\begin{array}{c}\text { Exp.* } \\
\text { value }\end{array}$ & $\begin{array}{c}\text { Pre.** } \\
\text { value }\end{array}$ & $\begin{array}{c}\text { Differ } \\
\text { ence }\end{array}$ & $\begin{array}{c}\text { Exp.* } \\
\text { value }\end{array}$ & $\begin{array}{c}\text { Pre. ** } \\
\text { value }\end{array}$ & Difference \\
\hline 1 & 525.0 & 0.45 & 3.0 & 77.72 & 77.26 & 0.46 & 530.68 & 626.56 & -95.88 \\
\hline 2 & 450.0 & 0.3 & 3.0 & 75.09 & 74.77 & 0.32 & 1142.10 & 1092.18 & 49.92 \\
\hline 3 & 525.0 & 0.3 & 2.0 & 74.23 & 76.07 & -1.84 & 540.20 & 543.79 & -3.59 \\
\hline 4 & 600.0 & 0.6 & 3.0 & 76.28 & 77.36 & -1.08 & 1065.96 & 1013.33 & 52.63 \\
\hline 5 & 450.0 & 0.6 & 1.0 & 55.12 & 55.05 & 0.07 & 921.30 & 863.73 & 57.57 \\
\hline 6 & 525.0 & 0.6 & 2.0 & 73.30 & 72.35 & 0.95 & 534.20 & 645.37 & -11.17 \\
\hline 7 & 525.0 & 0.45 & 2.0 & 74.07 & 71.37 & 2.7 & 510.14 & 433.63 & 76.51 \\
\hline 8 & 525.0 & 0.45 & 1.0 & 67.34 & 68.70 & -1.36 & 540.32 & 559.21 & -18.89 \\
\hline 9 & 600.0 & 0.3 & 1.0 & 76.24 & 76.16 & 0.08 & 769.01 & 762.52 & 6.49 \\
\hline 10 & 600.0 & 0.45 & 2.0 & 69.09 & 68.16 & 0.93 & 580.30 & 589.31 & -9.01 \\
\hline 11 & 600.0 & 0.3 & 3.0 & 77.35 & 77.19 & 0.16 & 753.79 & 782.66 & -28.87 \\
\hline 12 & 450.0 & 0.45 & 2.0 & 58.6 & 60.43 & -1.83 & 530.40 & 636.15 & -105.75 \\
\hline 13 & 525.0 & 0.45 & 2.0 & 74.07 & 71.37 & 2.7 & 510.14 & 433.63 & 76.51 \\
\hline 14 & 600.0 & 0.6 & 1.0 & 72.24 & 72.33 & -0.09 & 1058.35 & 1079.58 & -21.23 \\
\hline 15 & 525.0 & 0.45 & 2.0 & 74.07 & 71.37 & 2.7 & 510.14 & 433.63 & 76.51 \\
\hline 16 & 450.0 & 0.3 & 1.0 & 68.22 & 66.92 & 1.3 & 867.30 & 891.24 & -23.94 \\
\hline 17 & 450.0 & 0.6 & 3.0 & 75.56 & 75.41 & 0.15 & 1203.01 & 1178.29 & 24.72 \\
\hline
\end{tabular}

Table 4

EXPERIMENTAL DESIGN MATRIX AND RESULTS FOR PREPARATION OF AVOCADO SEED 


\section{Statistical analysis}

Results concerning the probabilities of each of the factors and their interactions as a function of each of the responses using the analysis of variance (ANOVA) are shown in table5. Factors are more significant when the confidence interval is $95 \%$, that is, a probability less than or equal to 0.05 .

Regression coefficients for $Y$ and $Y$ are shown in Table5. Thus, all regression equations of iodine number and $A C$ yield can be achieved according to these coefficients. Correlation coefficient of regression models of iodine number and $A C$ yield were 92.9742 and $96.36 \%$ and adjusted coefficient of regression were 83.941 and 91.67 $\%$, which meant a high fitting accuracy. There is only a $0.01 \%$ chance in both models occurring due to noise. Moreover, values of Prob $>$ F, less than 0.0500 , indicate that model terms are significant. In this table, we observe that: $A, B, C, A^{2}, A C, B C$ are significant for $A C$ yield and factors $A^{2}$, $A B, B^{2}$ and $C^{2}$ are significant for the iodine number. From the statistical results obtained, it was shown that the models were adequate to predict the avocado seed based activated carbon iodine number and yield, within the range of variables studied.

Accordingly, it was concluded that activation temperature, calcination time and concentration of agent activate influenced $\mathrm{AC}$ preparation significantly.
Mathematical modelling of the responses

Avocado seeds based activated carbon yield $\left(Y_{1}\right)$ and iodine number $\left(Y_{2}\right)$ in terms of coded factors, are represented by relations (5) and (6), respectively.

$$
\boldsymbol{Y}_{1}=277.726+1.40821 A-197.82 B+
$$

$+11.0465 C-0.00125778 A^{2}+0.084 A B-0.0369333 A C+$

$$
+126.444 B^{2}+13.75 B C+1.61 C^{2}
$$

$\boldsymbol{Y}_{2}=12286.1-35.9853 A-9831.44 B-222.146 C+$ $+0.0318408 A^{2}+7.65678 A B-0.602683 A C+7153.54 B^{2}-$

$$
-143.975 B C+159.255 C^{2}
$$

where:

$Y_{1}$ and $Y_{2}$ are yield and iodine number respectively;

$A$-Temperature,

$B$-Concentration,

C-Time.

The negative signs before the coefficients of independent and interaction factors indicate that they decrease the responses. Figure 1 shows the main effect plots of the factors on the responses.

\begin{tabular}{|c|c|c|c|c|c|c|c|}
\hline \multirow[t]{2}{*}{ Source } & \multirow[t]{2}{*}{ Df } & \multicolumn{3}{|c|}{$Y_{1}$ (Yield) } & \multicolumn{3}{|c|}{$Y_{2}$ (Iodine number) } \\
\hline & & SS & F-value & P-value & SS & F-value & P-value \\
\hline $\bar{A}$ & 1 & 149.073 & 31.63 & $0.0025^{\star}$ & 5484.5 & 0.62 & 0.4562 \\
\hline $\bar{B}$ & 1 & 34.7077 & 7.36 & $0.0421^{*}$ & 25797.3 & 2.93 & 0.1309 \\
\hline$C$ & 1 & 183.527 & 38.94 & $0.0015^{*}$ & 11340.1 & 1.29 & 0.2941 \\
\hline $\mathrm{AA}$ & 1 & 125.492 & 26.62 & $0.0036^{*}$ & 85946.2 & 9.75 & $0.0168^{*}$ \\
\hline $\mathrm{AB}$ & 1 & 7.1442 & 1.52 & 0.2730 & 59359.1 & 6.73 & $0.0357^{*}$ \\
\hline$A C$ & 1 & 61.3832 & 13.02 & $0.0154^{*}$ & 16345.2 & 1.85 & 0.2155 \\
\hline$\overline{\mathrm{BB}}$ & 1 & 20.2921 & 4.30 & 0.0927 & 69409.7 & 7.87 & $0.0263^{*}$ \\
\hline$\overline{B C}$ & 1 & 34.0313 & 7.22 & $0.0435^{*}$ & 3731.18 & 0.42 & 0.5361 \\
\hline $\mathrm{CC}$ & 1 & 6.4985 & 1.38 & 0.2932 & 67951.2 & 7.71 & $0.0274^{*}$ \\
\hline
\end{tabular}

It can be observed that the iodine number increases as the concentration and time increases and decreases with
Table 5

ANALYSIS OF VARIANCE (ANOVA) AS RESPONSE SURFACE QUADRATIC MODEL FOR AC YIELD AND IODINE NUMBER

$R^{2}=96.36 \% ; R^{2}$ adjusted $=91.67 \% ; R^{2}=92.9742 \%$, R2adjusted $=83.941 \%$

SS $=$ Sum of Squares, ${ }^{*}$ significantvalue, $F$-value $=$ Fisher value, $P$-value $=$ probability value .

$D f=$ degree of freedom
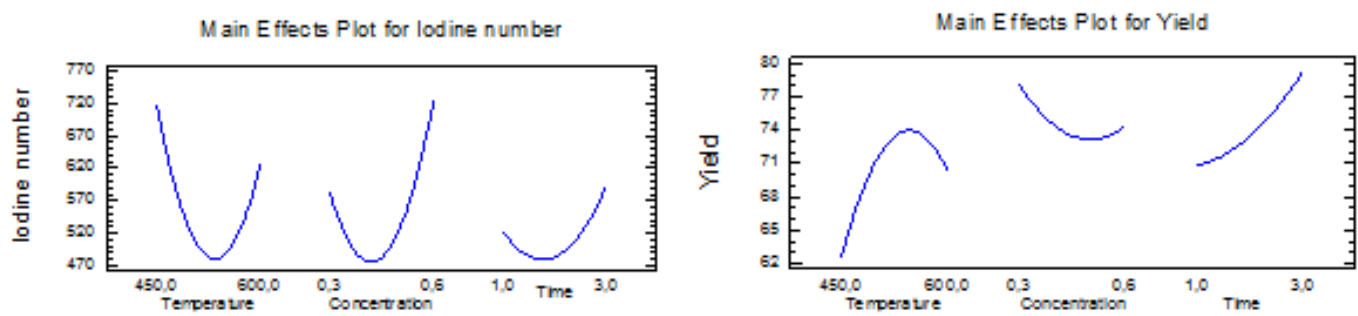

Fig. 1. Main effect plots of the factors on the responses
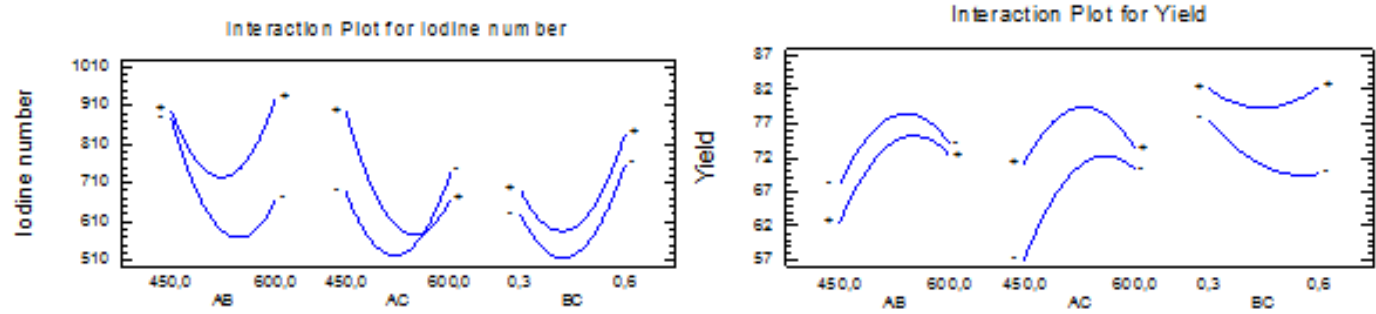
temperature. Concerning the effect of temperature on the yield, we can observe that increasing the temperature increases the yield. Also, it results thatby increasing the time, the yield increases.

\section{Optimize response}

The optimization method makes the location of an extreme point on the surface[24] possible. Based on achieving relative maximum iodine number and $A C$ yield, optimal preparation conditions of activation temperature, activation time and concentration of agent activate were calculated by design-Expert software version 5 . under conditions of $450^{\circ} \mathrm{C}, 3 \mathrm{~h}$ and $0.3 \mathrm{~mol} / \mathrm{L}$, iodine number reached the relatively highest values of $1092.18 \mathrm{mg} / \mathrm{g}$ and AC yield $82.59 \%$ for $538.78{ }^{\circ} \mathrm{C}, 3 \mathrm{~h}$ and $0.6 \mathrm{~mol} / \mathrm{L}$ respectively. Furthermore, to test accuracy of the value achieved by above model, optimized experimental conditions for AC preparation were carried out.

\section{Response surface}

The fitted response surface plot was generated by statistically significant above model design Expert program to understand the interaction of the parameters required for optimum iodine number and ACyield. At each point of the domain corresponds aresponse. The value that a response can take within the field of study can be predicted. The diagrams of the response surfaces thus offer the possibility to see the evolution of the different responses. One can thus note the synergistic effect of all the factors on the different responses.

\section{lodine number}

Figure 2 ( $a$ and $b$ ) shows the three -dimension response surfaces which were constructed to show the interaction effects. Figure $2 \mathrm{c}$ shows the Pareto Chart for the iodine number. These diagrams allow identifying the combination of input variable parameters that jointly optimize a single response or set of responses. They also allow evaluating the impact of the activating agent, the calcination temperature and the residence time in the furnace on the iodine number and $A C$ yield.

As it can be seen from figure 2 ( $a, b$ and $c)$, that the iodine number increased with increased activation temperature, and decreases with increased concentration of the activating agent. The valus have an effect on the porosity of the activated carbon [10]. The synergistic effect of the various factors on the response is thus verified.

\section{Activated carbon yield}

Figure 3 shows the three-dimensional response surface plot of AC yield; (a) effect of concentration and activation temperature, time $=3 \mathrm{~h}$, (b) effect of concentration and activation time, $\mathrm{T}=535.74^{\circ} \mathrm{C}$.

From the observation of these figures and in agreement with the results of values presented in table 5 , one can

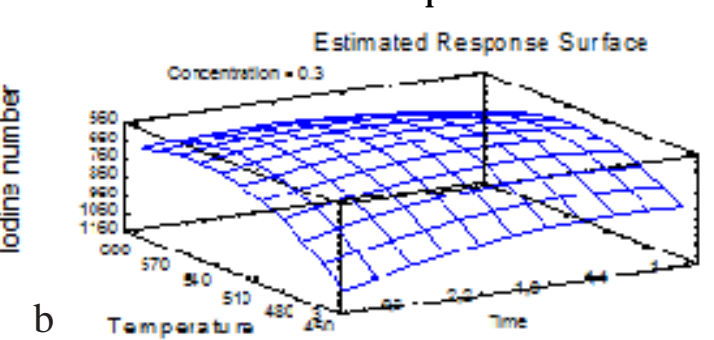

Fig. 2. Three -dimension response surfaces with fixed time (a), Three -dimension response surfaces with fixed concentration (b), Pareto Chart for iodine number (c)
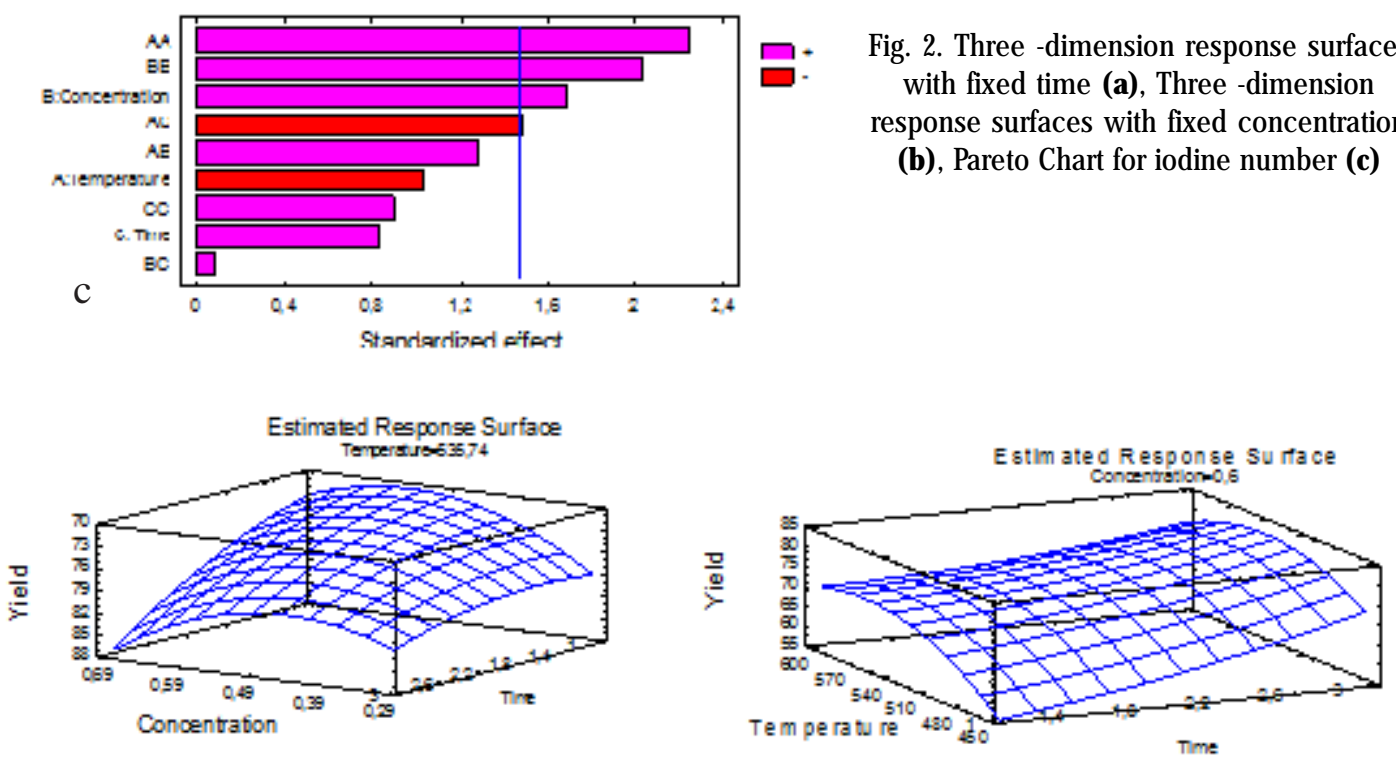

(a)(b)

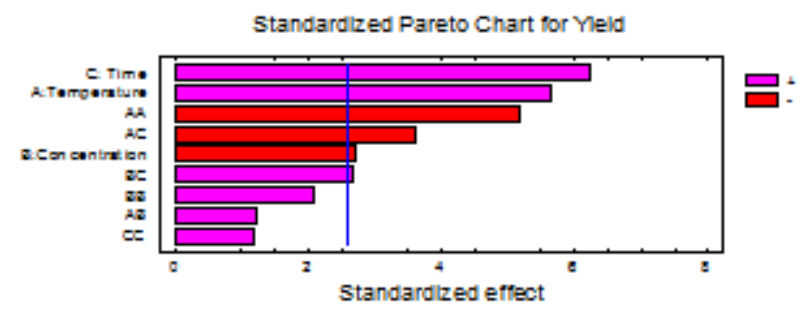

Fig. 3. Three - dimension response surfaces with fixed temperature (a), Three - dimension response surfaces with fixed concentration (b), Pareto Chart for yield (c) 
confirm that the temperature and time imposethe greatest effect on AC yield, followed by concentration. The interaction effects between the activation temperature and concentration, as well asactivation time and concentration,were considered high.

\section{Optimum values}

The statistical software was used to obtain the optimum preparation parameters in relation to the responses considered. The Statgraphic Plus5 software considered the unit factor effect, two factors interaction and quadratic factors impact on the resulting models which ordinarily are tedious or impossible with maximum accuracy to execute manually. The optimum values of the responses, as well as the values of the factors that make it possible to obtain these values, are summarized in table 6 . These values are the result of the superposition of the different curves of response surfaces. The area of interest is the one found in optimal conditions.

\section{Characterization of Activated Carbon}

Fourier Transform Infrared Spectroscopy (FTIR)

Fourier transform infrared (FTIR) transmission spectra were obtained to characterize the surface groups on the Avocado seeds and the AC prepared from these precursors. The infrared spectroscopic analysis spectra of the various adsorbents are shown in figures 4 and 5 . Examination of these spectra reveals the presence of several absorption bands of valence and deformation vibrations attributable to the different groups existing in these materials. The different vibration bands identified were assigned using the results of the literature on the characterization of lignocellulosic materials [27].

The first band appears at $3330 \mathrm{~cm}^{-1}$ due to the vibration of elongation of $\mathrm{O}-\mathrm{H}$ functions. The bands of vibrationof elongation of the $\mathrm{C}-\mathrm{H}$ functions are raised between 3000$2840 \mathrm{~cm}^{-1}$, with a larger intensity around $2920 \mathrm{~cm}^{-1}$. One also observes the appearance of a band to $1730 \mathrm{~cm}^{-1}$ corresponding to the vibration of elongation of $\mathrm{C}=0$ functions. The band ofelongation $\mathrm{C}=\mathrm{C}$ of the aromatic skeleton of lignin is also visible on these spectra; it appears around $1580 \mathrm{~cm}^{-1}$. In the spectral area $1150-1000 \mathrm{~cm}^{-1}$, a band of great intensity (cantered at $1030 \mathrm{~cm}^{-1}$ ) appears, corresponding to the vibration of elongation C-O [27].

\section{Scanning Electronic Microscope (SEM)}

The images of the surface morphology of the best activated carbon obtained at $450^{\circ} \mathrm{C}, 0.3 \mathrm{~mol} / \mathrm{L}$ and $3 \mathrm{~h}$, as well as the raw biomasses are illustrated in figure 6 .

These images show that the active carbon induces a consequent development of the porosity by bursting of the naturally occurring pores in the biomass or induced by activation and pyrolysis. The aim of the SEM examination is to illustrate the porosity, especially that created by activated carbon. A developed porosity makes it possible to increase the specific surface area of the coal and, consequently, the number of active sites on which may be fixed molecules of interest.

\begin{tabular}{|c|c|c|c|c|c|c|c|c|}
\hline \multirow{2}{*}{$\mathrm{X} 1\left({ }^{\circ} \mathrm{C}\right)$} & \multirow{2}{*}{$\mathrm{X} 2(\mathrm{~mol} / \mathrm{L})$} & \multirow{2}{*}{$\mathrm{X} 3(\mathrm{~h})$} & \multicolumn{3}{|c|}{ Iodine number $(\mathrm{mg} / \mathrm{g})$} & \multicolumn{3}{|c|}{ Yield (\%) } \\
\hline & & & Predicted & Experimental & Error (\%) & Predicted & Experimental & Error $(\%)$ \\
\hline 450 & 0.3 & 3.0 & 1092.18 & 1142.10 & 49.92 & 82.51 & 75.09 & 7.52 \\
\hline
\end{tabular}

Table 6 MODEL VALIDATION

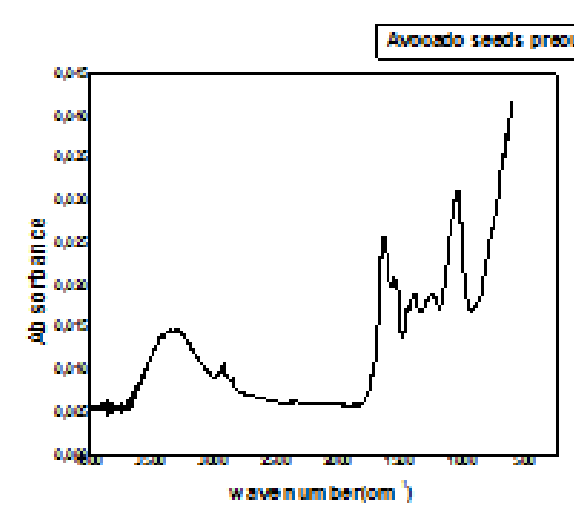

Fig.4. FTIR spectra of raw avocado seeds

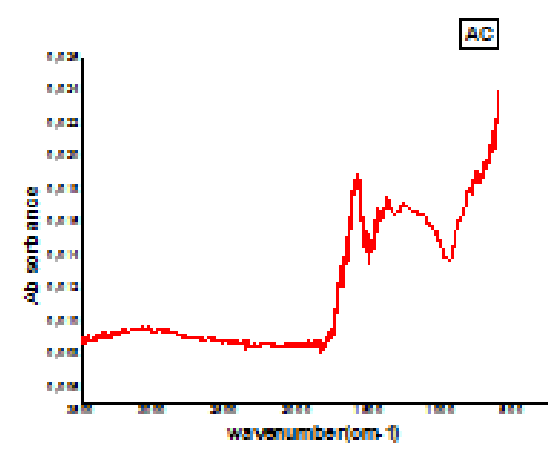

Fig.5. FTIR spectra of avocado seeds based AC

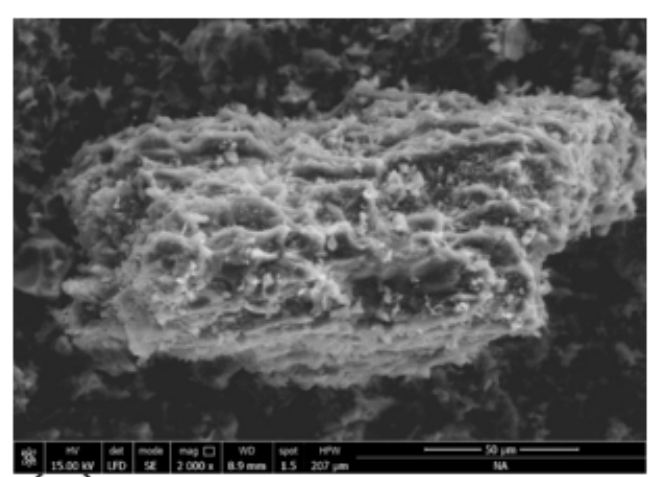

(a)

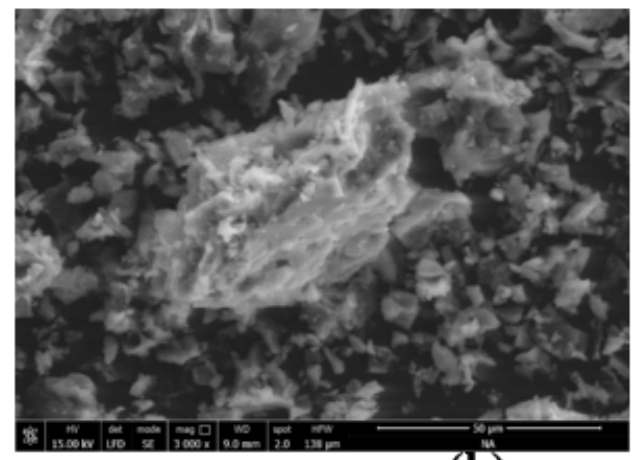

(b)

Fig.6. SEM images for raw biomass(a) and activated carbon (b) (voltage $15 \mathrm{kV}$ and 3000x magnification). 


\section{Conclusions}

The analysis of the experimental design through the response surface methodology (composite design plant) was used to study the main factors (carbonization temperature, pyrolysis duration and concentration of the activating agent) on the yield and the adsorption properties measured by the iodine number during the preparation of activated carbons. The influences of its various factors on the responses have been modelled by a quadratic model of the second order in satisfactory ways.

The optimum avocado pear based activated carbon was obtained by using activation temperature, activation time and concentration of $450^{\circ} \mathrm{C}, 3.0 \mathrm{~h}$ and $0.3 \mathrm{~mol} / \mathrm{L}$, respectively, thus resulting an iodine number $1142.10 \mathrm{mg} /$ $g$, and AC yield of $82.51 \%$. The avocado pear, prepared based activated carbon, demonstrated high surface area and well-developed porosity.

Acknowledgements: The authors are grateful for the support of the research work for Mr TagneTiegam Rufis Fregue, through the University Agency of Francophonie (AUF) via the program EUGEN IONESCU 2017/2018, hosted by the Politehnica University of Timisoara (Romania). Also the PhD position of Alin-Cristian Mihaiuti, at the same university, is acknowledged.

\section{References}

1. ZAINESCU, G.A., CONSTANTINESCU, R.R., VOICU, P., DESELNICU, D.C., Rev. Chim.(Bucharest), 67, no.1, 2016, p. 48.

2. MOHD, A.A., RASYIDAH, A., Optimization of rambutan peel based activated carbon preparation conditions for Remazol Brilliant Blue R removal, Chemical Engineering J ournal, 168 (2011), p. 280-285.

3. FOO, K.Y., HAMEED, B.H., Microwave-assisted preparation of oil palm fibber activated carbon for methylene blue adsorption. Chemical Engineering Journal,166 (2011), p.792-795.

4. AHMAD,A.A.,HAMEED,B.H., Effect of preparation conditions of activated carbon from bamboo waste for real textile wastewater. J ournal ofHazardous Materials, 173 (2010), p.487-493.

5. GIRGIS, B.S., SMITH, E., LOUIS, M. M., EL-HENDAWY,A. A., Pilot production of activated carbon from cotton stalks using $\mathrm{H}_{3} \mathrm{PO}_{4^{\prime}}$ J ournal of analytical and applied pyrolysis, 86(2009), p. 180-184.

6. GUO, J., LUA, A.C., Characterization of adsorbent prepared from oilpalm shell by $\mathrm{CO}_{2}$ activation for removal of gaseous pollutants, Materials Letters, $\mathbf{5 5}$ (2002), p. 334-339.

7. CARROTT, P.J.M., MOURAO, P.A.M., CARROTT, M.M.L.R., Controlling the micro pore size of activated carbons for the treatment of fuels and combustion gases. Applied Surface Science, 252 (2006b), p.59535956.

8.GUPTA,V.K. ANDSUHAS, S.,Pareto Chart for iodine number, Application of low-cost adsorbents for dye removal-a review, Environ. Manage., 90 (2009), p. 2313-2342.

9. DIASA, J .M., ALVIM-FERRAZA, M.C.M., ALMEIDAA, M. F., SANCHEZPOLO. M., Waste materials for activated carbon preparation and its use in aqueous-phase treatment: A review. J ournal of Environmental Management, 85 (2007), p. 833-846.

10. AHMAD, M. A.,ALROZI, R., Optimization of preparation conditions for mangosteen peel-based activated carbons for the removal of Remazol Brilliant Blue R using response surface methodology. Chemical Engineering J ournal, 165 (2010), p. 883-890.

11. BENADJ EMIA, M., MILLIERE, L., REINERT, L., BENDERDOUCHE, N., DUCLAUX, L., Preparation, characterization and Methylene Blue adsorption of phosphoric acid activated carbons from globe artichoke leaves. Fuel Processing Technology, 92 (2011), p. 1203-1212.

12. FANG,K.T., The uniform design: application of number-theoretic methods in experimental design.ActaMathematicaSinica, 3 (1980), p. 363-372.
13. CHAN, L,. JINGHUA, B., ZHOALIN, C.,YANG, F., Optimization of cultural medium for bacteriocin production by Lactococcuslactis using response surface methodology. Journal of Biotechnology, 93 (2002), p. 27-34.

14. SUDARYANTO,S.B., HARTONO,W.,IRAWATY, H.,HINDARSO,S., ISMADJ I., High surface area activated carbon prepared from cassava peel by chemical activation, BioresourceTechnology. 97 (2006), p. 734-739.

15. VARGAS, A.M.M., GARCIA, C. A., REIS,E. M.,LENZI, E., COSTA, W. F., ALMEIDA,V. C., NaOH-activated carbon from flamboyant (Delonixregia) pods: Optimization ofpreparation conditions using central composite rotatable design. Chemical Engineering J ournal, 162 (2010), p. 43-50.

16. EL-HENDAWY, A.A., SAMRA, S.E., GIRGIS, B.S., Adsorption characteristics of activated carbons obtained from corncobs, Colloids and Surfaces A, 180 (2001),p. 209-221.

17. LILLO-RODENAS, M.A., CAZORLA-AMOROS, D.,LINARES, S,A., Understanding chemical reactions between carbons and $\mathrm{NaOH}$ and $\mathrm{KOH}$ : an insight into the chemical activation mechanism. Carbon 2003; 41(2), p.267-75.

18.ADINATA, D., DAUD, W.M.A.W., AROUA, M.K., Preparation and characterizationof activated carbon from palm shell by chemical activation with $\mathrm{K}_{2} \mathrm{CO}_{3^{\prime}}$ Bioresource technology, 98 (2007), p. 145-149. 19. LILLO-RODENAS, M.A., LOZANO-CASTELLO, D., CAZORLAAMOROS, D., LINARES-SOLANO, A., Preparation of activated carbons from Spanish anthracite II.Activation by $\mathrm{NaOH}$. Carbon, 39 (2001), p. 751-759.

20. WU, F.C.,T SENG, R.L., High adsorption capacity $\mathrm{NaOH}$-activated carbon for dye removal from aqueous solution. Journal of Hazardous Materials 152 (2008), p. 1256-1267.

21. Suzuki, M., Adsorption Engineering, Kodansha Ltd. and Elsevier Science Publishers B.V., Tokyo and Amsterdam, 1990.

22. FIERRO, V., TORNE-FERNANDEZ, V., CELZARD, A., Methodical study of the chemical activation of Kraft lignin with $\mathrm{KOH}$ and $\mathrm{NaOH}$. Microporous and MesoporousMaterials, 101 (2007), p. 419-431.

23. ALAM, M.Z., MUYIBI, S.A.,T ORAMAE, J.,Statistical optimization of adsorption processes for removal of 2,4-dichlorophenol by activated carbon derived from oil palm empty fruit bunches, Journal of Environmental Sciences,19 (2007),p. 674-677.

24. SIBIESCU, D., CRETESCU, I., Pareto Chart for iodine number, Rev. Chim.(Bucharest), 67, no. 1, 2016, p. 136-137.

25. MARINOIU, A.,CARCADEA, E., COBZARU, C., CERNATESCU, C., Rev. Chim.(Bucharest), 68, no.1, 2017, p. 130.

26. *** European Standard EN 14774, Solid biofuels -Determination of moisture content -Oven dry method, (2009).

27. KENNE, D.G., Implication des materiaux lignocellulosiques dans la résolution des problemslies a la pollution de l'eau par le paraquat: Etude du processus de biosorption mis enjeu et elaboration de capteurselectrochimiques a film de sciure de bois. These de Doctorat/ Ph.D, Universite de Yaounde I,Cameroun (Implication of lignocellulosic materials in the resolution of the problems related to the water pollution by the paraquat: study of the biosorption process put stakes and elaboration of electrochemical sensors with sawdust film. PhD doctoral thesis, Universityof Yaounde, Cameroon), (2011), p. 5-97.

28. FERNANDEZ, E., Etude de la carbonisation et de l'activation de précurseurs vegetaux dures et mous, PhDThèse de Doctorat, (Study of carbonisation and activation of hard and soft plant precursors, PhDThesis), 2002 (Universite NEUCHATEL)

$\overline{\text { Manuscript received: } 11.07 .2018}$ 